\title{
O PROGRAMA DE QUALIDADE DA ESCOLA DO ESTADO DE SÃO PAULO ${ }^{1}$
}

\author{
Adriana de Castro ${ }^{2}$ \\ Roseli Esquerdo Lopes ${ }^{3}$
}

\section{RESUMO}

Em 2008, a Secretaria de Estado da Educação de São Paulo (SEE/SP) implantou o "Programa de Qualidade da Escola" (PQE) com a finalidade de avaliar cada escola por meio de metas anuais, pré-estabelecidas, com base em dois critérios: o fluxo escolar e o desempenho dos alunos no Sistema de Avaliação do Rendimento Escolar do Estado de São Paulo. Este trabalho propõe-se a discutir o PQE, como um instrumento de melhoria da qualidade educacional, tendo como parâmetros os documentos oficiais, os dados de uma pesquisa empírica (abrangendo oito polos da SEE/SP e três escolas jurisdicionadas à Diretoria de Ensino Região de Pirassununga) e sua análise a partir do arcabouço teórico. Dentre suas principais conclusões, pode-se afirmar que fatores intra e extraescolares compõem a qualidade educacional, tanto para a SEE/SP, como para os sujeitos pesquisados. Apesar disso, a organização escolar enfatiza o produto sobre o processo educacional.

Palavras-chave: Educação; Políticas Públicas; Escola Pública; Programa de Qualidade da Escola.

\section{THE SCHOOL QUALITY PROGRAM OF SÃO PAULO STATE (BRASIL)}

\begin{abstract}
In 2008, the Education Department of São Paulo State (SEE/SP) implemented the "School Quality Program" with the purpose of evaluating each school through pre set annual goals based on two criteria: the school flow and the student performance in the Evaluation System of School Performance in São Paulo State. This paper is to discuss the "PQE", as an instrument of improving educational quality, with the official documents parameters, the data from empirical research (covering eight cities in "SEE/SP" and three schools that belong to Pirassununga's Region Education Directorship) and its analysis from the theorical framework. Among its key findings, it can be said that school intra and extra factors make up the quality of education for both the "SEE/SP", as to the subjects studied. Despite this, the school organization emphasizes the product on the educational process.
\end{abstract}

Keywords: Education; Public Policy; Public School; School Quality Program. 


\section{Introdução}

No dia 20 de agosto de 2007, o governador José Serra (gestão 2007-2010) e a secretária de educação do estado de São Paulo, Maria Helena Guimarães de Castro anunciaram um plano amplo para a educação paulista com dez metas a serem atingidas pelas escolas estaduais até o ano de 2010. Juntamente com essas metas, o governo paulista lançou o Programa de Qualidade da Escola (PQE), com a finalidade de "instituir critérios objetivos para a avaliação das escolas da rede estadual paulista e para o estabelecimento de metas que promovam a melhoria da qualidade e da equidade do sistema" (SÃO PAULO, 2007a, p.5).

Para isso, foi criado o Índice de Desenvolvimento da Educação do Estado de São Paulo (o IDESP), que, a partir de cálculos matemáticos, com base na taxa média de aprovação dos alunos e no desempenho por eles alcançado no Sistema de Avaliação do Rendimento Escolar do Estado de São Paulo (SARESP) ${ }^{4}$, apontou o índice atingido pela escola nas $4^{\text {as }} \mathrm{e}$ $8^{\text {as }}$ séries do ensino fundamental ${ }^{5}$ e $3^{\text {as }}$ séries do ensino médio, no ano de 2007 e as metas a serem alcançadas no ano subsequente.

Todas as escolas deverão atingir, até o ano de 2030, apurado o IDESP de 2007, as seguintes metas: 7,0 e 6,0 nas $4^{\text {as }}$ séries e $8^{\text {as }}$ séries do ensino fundamental, respectivamente, e 5,0 nas $3^{\text {as }}$ séries do ensino médio. O objetivo dessa projeção, em longo prazo, é alcançar níveis parecidos com os dos países da Organização para a Cooperação e o Desenvolvimento Econômico (OCDE), "que são os mais bem colocados do mundo em termos de qualidade da educação" (SÃO PAULO, 2008a, p. 14).

Neste trabalho, nosso propósito é discutir o Programa de Qualidade da Escola, como um instrumento de melhoria da qualidade educacional, tendo como parâmetros os objetivos proclamados pela SEE/SP, os dados de uma pesquisa empírica e sua análise a partir do arcabouço teórico.

O recorte empírico para a coleta de dados abrangeu oito dos nove pólos que compunham a Coordenadoria de Ensino do Interior da SEE/SP e o estudo de caso deu-se em três escolas jurisdicionadas à Diretoria de Ensino Região de Pirassununga. Os resultados dizem respeito à visão de gestores, alunos, pais e professores e são articulados aos indicadores referentes aos índices de desenvolvimento da educação de cada uma dessas escolas, nos anos de 2008 e 2012.

Na primeira parte deste texto, tratamos do vínculo existente entre a qualidade educacional e a avaliação; a seguir, apresentamos, tomando-se sua proposição oficial, o Programa de Qualidade da Escola e o Índice de Desenvolvimento da Educação do Estado de São Paulo (IDESP). Na terceira parte, expomos os dados empíricos encontrados, buscando correlacioná-los às pretensões do PQE, discutindo seus limites.

\section{A Qualidade Educacional Nos Documentos Oficiais E Sua Interface Com A Avaliação}

O artigo 205 da Constituição da República Federativa do Brasil de 1988 (CF) estabelece a educação como direito de todos, e é dever do Estado e da família promovê-la com o apoio da sociedade. A educação, aqui entendida de maneira ampla, para além dos muros escolares, tem como fins: o pleno desenvolvimento da pessoa humana, o preparo para o exercício da cidadania e sua qualificação para o trabalho. É uma educação que não desconsidera o indivíduo e seu desenvolvimento, mas extrapola esse objetivo ao pleitear integrá-lo à sociedade produtiva.

Cria-se um círculo virtuoso por meio da educação, já que melhorias nessa área geram ganhos sociais que repercutem na eficiência dos investimentos: 
Os ganhos da escolaridade no presente se refletem diretamente sobre a educação de gerações futuras e, indiretamente, através dos ganhos de cidadania, sobre a eficiência dos investimentos sociais [...]. A extrema desigualdade de renda no país é sintomática das limitações existentes a um exercício mais amplo e mais intenso da cidadania, especialmente em seus direitos sociais, como o direito ao trabalho e à vida digna (SOUZA, 2005a, p. 100).

Quanto à "garantia de padrão de qualidade" (inciso VII do artigo 206 da CF), ela não é explicitada nem detalhada, deixando essa problemática em aberto.

O Custo Aluno Qualidade Inicial (CAQi) tornou-se referência ao "apresentar com clareza os insumos necessários a esse direito" (BRASIL, CNE, CEB, 2010). Esses insumos contemplam desde o prédio até os equipamentos e recursos humanos para atender às diferentes etapas da educação básica, prevendo a progressiva extensão do tempo diário de atividades para o aluno.

A obrigatoriedade da elaboração do Plano Nacional de Educação (artigo 214 da CF) está instituída com o objetivo claro de articular e desenvolver o ensino em seus diversos níveis, integrando as ações do poder público. Para atender aos artigos 210 e 214 da Constituição, o Ministério da Educação e do Desporto estruturou um processo de avaliação em escala nacional com o Sistema Nacional de Avaliação da Educação Básica, o SAEB, com início em 1990. Na opinião da presidenta do Instituto Nacional de Estudos e Pesquisas Educacionais (INEP), no período de 1995 a 2002, os mecanismos de monitoramento e acompanhamento das informações e políticas mostram-se necessários para corrigir eventuais falhas no percurso e para dar transparência ao que é feito numa democracia (CASTRO, 2000). O SAEB vem fomentando, desde sua criação, aportes para uma cultura avaliativa no país, que busca impulsionar estados e municípios a avaliarem suas escolas (Pestana, 2009). Essa avaliação de sistema tem como base:

O modelo CIPP (contexto, insumo, processo, produto) serviu, então, de base para a estruturação de uma avaliação de sistema educacional, uma vez que, com as adequações necessárias, possui amplitude suficiente para prover informações sobre diferentes aspectos da situação educacional: rendimento de alunos, atuação de professores, supervisores e administradores, eficácia de programas, currículos e processos de ensino, infraestrutura e condições de funcionamento das escolas etc. (PESTANA, 2009, p. 59).

O modelo CIPP é claramente um modelo industrial de linha de produção: o contexto é a escola; o insumo, o aluno; o processo, o processo educativo; e o produto é o resultado nas avaliações externas. Nesse sentido, o contexto, o insumo e o processo são considerados apenas como fonte de informações porque o resultado, o produto, tem de ser alcançado, independentemente das reais condições das escolas.

Apoiados em outros pesquisadores da área, Oliveira e Novaes (2012) analisaram os efeitos dos resultados da avaliação em larga escala sobre a gestão das escolas públicas. Eles assinalam que, nos Estados Unidos, vários estados adotaram a política de school accountability (SA). Andrade (2008) esclarece que essa política possui alguns aspectos gerais:

(i) estabelecimento de padrões educacionais mínimos para cada ano escolar; (ii) realização de testes de proficiência para averiguar os conhecimentos adquiridos pelos alunos; (iii) divulgação dos resultados dos testes por escola; e (iv) adoção como objetivo explícito de política a melhoria no desempenho dos estudantes nestes testes (ANDRADE, 2008, p. 443). 
Vale lembrar que, atualmente, a SA sofre críticas nos Estados Unidos. Em pesquisa divulgada em julho de 2011, não foi comprovada uma relação linear entre o recebimento do bônus pelo professor e um melhor desempenho do aluno, acarretando a supressão, pela cidade de Nova Iorque, dessa política (OLIVEIRA \& NOVAES, 2012).

Saviani (2008) alerta que essas avaliações refletem a mudança do papel do Estado, que as utiliza para regular as ações das escolas:

Redefine-se, portanto, o papel tanto do Estado como das escolas. Em lugar da uniformização e do rígido controle do processo, como preconizava o velho tecnicismo inspirado no taylorismo-fordismo, flexibiliza-se o processo, como recomenda o toyotismo. Estamos, pois, diante de um neotecnicismo: o controle decisivo desloca-se do processo para os resultados (SAVIANI, 2008, p. 439, grifo nosso).

Nosella (2010) afirma que, "em suma, a cultura do desempenho é a negação da pedagogia como espaço profissional de humanização por meio de atividades ético-científicas" (NOSELLA, 2010, p. 30). Na SEE/SP, com a criação do IDESP, passa a haver uma ênfase na coleta e na disseminação dos resultados.

A Lei de Diretrizes e Bases da Educação Nacional (LDBEN) - Lei n 9.394, de 20 de dezembro de 1996 (BRASIL, 1996) disciplina apenas a educação escolar, com as mesmas finalidades dispostas na CF de 1988. A qualidade de ensino, nesse texto legal, é entendida como variedade e quantidades mínimas de insumos per capita, demonstrando claramente que ela está associada a livros, computadores, quantidade de alunos por classe, quantidade de horas etc., mas tudo em relação mínima suficiente, em quantidades mínimas. A qualidade é consubstanciada nessa lei como insumos que poderão tornar o ensino mais eficaz, como uma aplicação em que se gasta/investe o mínimo e obtêm-se dividendos e retornos no menor prazo.

Com a apresentação do Plano de Desenvolvimento da Educação (PDE), no ano de 2007, o governo federal buscou executar o Plano Nacional de Educação (PNE), estabelecido em 2001. Como objetivo principal do PDE, podemos mencionar a melhoria da qualidade educacional, para a qual foi criado, no ano de 2007, um indicador, o IDEB ${ }^{6}$.

Ante a centralidade que a avaliação de resultados adquire no cenário educacional, como base para a elaboração de políticas educacionais, a partir da década de 1980, muitos autores adotam a expressão 'Estado Avaliador' para defini-lo. Segundo Afonso (2009):

esta expressão quer significar, em sentido amplo, que o Estado vem adoptando um ethos competitivo, neodarwinista, passando a admitir a lógica do mercado, através da importação para o domínio público de modelos de gestão privada, com ênfase nos resultados ou produtos dos sistemas educativos (AFONSO, 2009, p. 49, grifo no original).

Para Zanardini (2008), o Estado Avaliador apresenta-se não como um financiador de políticas educacionais, mas como um controlador, regulador e incentivador dessas políticas, em consonância com os ditames do Banco Mundial (BM), nos quais a educação é um incremento para a redução necessária da pobreza de alguns países que contam com seu auxílio financeiro, com vistas à formação mínima de consumidores de bens.

Kruppa (2001) ao estudar a atuação do BM no Brasil, nos anos de 1990, afirma que:

o inventário conceitual da educação escolar, feito pela análise dos documentos produzidos pelo Banco para o setor, constatou a ampliação de 
sua interferência no país: os projetos pontuais e mais localizados dos anos de 50 a 70, que marcam o início de sua atuação no Brasil, modificam-se no sentido de serem portadores de uma visão decisivamente sistêmica e abrangente e que se apresenta, pelo menos, de três maneiras. Em primeiro lugar, pela definição de concepções e de formas de atendimento relativas a todos os níveis educacionais [...]. Em segundo lugar, em torno do princípio de governabilidade [...] com a proposta de processos de descentralização, mas com a construção de uma engenharia de controle centralizada, baseada na forte ênfase à padronização (do currículo ao conjunto de insumos/inputs do sistema) e da montagem de um sistema potente de avaliação, bases fundamentais do processo de reforma implantado nos anos 90 [...]. Em terceiro lugar, e não menos importante, pela definição das formas de financiamento [...] (KRUPPA, 2001, p. 1-4).

A educação, para o BM, é tida como estratégia para o desenvolvimento dos países devedores em uma dupla dimensão: "redução da pobreza e requisito fundamental para o aumento da produtividade" (SOUZA, 2005b, p.103), conferindo prioridade à educação básica. Assim, "as concepções educacionais ancoradas nos princípios de equidade, produtividade e redução do estado de pobreza estão subordinadas à lógica da racionalidade econômica" (SOUZA, 2005b, p.107).

De acordo com esse autor, a influência do BM, no contexto do final dos anos 1980 a meados da década de 1990, foi significativa na definição da política educacional não só no estado de São Paulo como para o País, especialmente se tomado como fonte financiadora de recursos para a educação pública (SOUZA, 2005b).

Nesse sentido, consideramos oportuna a análise de Zanardini (2008), cujo excerto reproduzimos abaixo:

O modo de produção capitalista, em seu atual estágio de desenvolvimento, exige e implementa processos e mecanismos de avaliação tendo em vista avaliar e controlar o sucesso ou fracasso das proposições educacionais que implementa. Consoante a esse processo, o Estado avaliador regula o investimento em educação, decorrendo daí a importância dos mecanismos de avaliação tomados em seus resultados como parâmetro de investimento na área. Dessa forma, a avaliação educacional, ademais de servir de mecanismo de controle social, cumpre o objetivo de regular os investimentos em educação (ZANARDINI, 2008, p. 22).

Afonso alerta para a outra faceta das avaliações, para além da aprendizagem dos alunos: "as funções simbólicas, de controle social e de legitimação política, apesar de menos referidas, são funções que têm um maior interesse analítico quando se problematiza a avaliação para além dos limites mais restritos do espaço pedagógico" (AFONSO, 2009, p. 19).

\section{O Programa de Qualidade da Escola}

O PQE, assim como o Índice de Desenvolvimento da Educação do Estado de São Paulo (IDESP), foi estabelecido pela Resolução SE n ${ }^{\circ} 74$, de 6/11/2008, e tem como objetivos:

garantir o direito fundamental de todos os alunos das escolas estaduais paulistas poderem aprender com qualidade e a necessidade de disponibilizar à unidade escolar diferentes indicadores de natureza 
quantitativa e qualitativa que forneçam diagnósticos acerca da qualidade do ensino oferecido e possibilitem a definição de metas exeqüíveis (SÃO PAULO, 2008c).

Foram propostos diferentes indicadores, conforme veremos a seguir, de natureza quantitativa e qualitativa para estabelecer a qualidade do ensino atual da escola e a almejada. Esses indicadores passam a constituir um parâmetro que garantiria, de acordo com o exposto acima, que todos os alunos aprendam com qualidade, além de fornecerem subsídios a serem administrados pela equipe escolar. À época, a secretária afirmou ainda que o IDESP seguiria a mesma linha do Índice de Desenvolvimento da Educação Básica (IDEB), proposto pelo governo federal ${ }^{7}$ no Plano de Desenvolvimento da Educação (PDE), tanto na forma a ser calculado quanto aos seus objetivos.

No artigo $1^{\circ}$ da Resolução SE $n^{\circ} 74$, encontram-se descritas as três finalidades do PQE, de acordo com a Secretaria de Estado da Educação de São Paulo - SEE/SP, que podem ser sintetizadas também em três palavras: (construir e indicar) índices, (estabelecer) metas e ações (para alcançar as metas estabelecidas, aprimorando, ou não, os índices). Com base nisso, a SEE/SP orientou as equipes escolares a organizar o trabalho visando ao alcance das metas.

O IDESP ${ }^{8}$ é o aporte instrumental do PQE que, desde o início de 2008, indica o que se denomina como a qualidade das escolas individualmente. Ele subsidia o "I - cálculo de metas de qualidade fixadas para cada unidade escolar; [e] II - o indicador coletivo específico a ser utilizado na atribuição da bonificação por desempenho ou mérito dos servidores" (artigo $3^{\circ}$ da Resolução SE $n^{\circ} 74$ ).

O desempenho do grupo discente é medido pelos resultados obtidos pelos alunos dos $5^{\circ} \mathrm{s}$ e $9^{\circ} \mathrm{s}$ anos do ensino fundamental e da $3^{\mathrm{a}}$ série do ensino médio nas avaliações de língua portuguesa e de matemática do SARESP, de acordo com os níveis de proficiência (Abaixo do Básico, Básico, Adequado e Avançado) definidos em relação às expectativas de aprendizagem em cada componente curricular, consubstanciando-se no indicador de desempenho (ID). A "taxa média de aprovação nas séries iniciais $\left(1^{\mathrm{a}}\right.$ a $4^{\mathrm{a}}$ série $)$ e finais do $\mathrm{EF}^{9}\left(5^{\mathrm{a}}\right.$ a $8^{\mathrm{a}}$ série) e do $\mathrm{EM}^{10}\left(1^{\mathrm{a}}\right.$ a $3^{\mathrm{a}}$ série), coletada pelo Censo Escolar" (SÃO PAULO, 2007b, p. 9) formam o indicador de fluxo (IF). Ou seja, IDESP ${ }_{s}=I_{s} \times I_{s}$, onde o IDs é o indicador de desempenho da série "s" e IFs é o indicador de fluxo da série "s", e "s" representando o $5^{\circ}$ ou o $9^{\circ}$ ano do ensino fundamental ou ainda a $3^{\mathrm{a}}$ série do ensino médio.

A partir desses dados, são estipuladas metas anuais ${ }^{11}$ para cada escola em todos os níveis de ensino pela SEE/SP, que estabelece, no início de cada ano, as metas para os indicadores específicos de cada unidade escolar.

A SEE/SP divulgou, no dia 11 de dezembro de 2008 (SÃO PAULO, 2008b), que o cumprimento das metas do IDESP pela equipe escolar representaria um incentivo financeiro $^{12}$ de até 2,9 salários mensais para todos os funcionários envolvidos (desde o agente de serviços escolares até o diretor da escola) e que a equipe que não atingisse a meta seria apoiada pela supervisão e pelo professor coordenador ${ }^{13}$. Como há a possibilidade do mesmo professor atuar em níveis distintos de ensino, sua bonificação fica atrelada ao nível em que possuir maior carga horária. O mesmo ocorre com os professores coordenadores: "os demais servidores das unidades escolares cujas funções não se restringem a níveis de ensino específicos recebem pelos indicadores agregados das escolas em que atuam" (SÃO PAULO, 2013).

Para a SEE/SP, no contexto do IDESP, a Bonificação por Resultados (BR) "surge com o objetivo de motivar nossos profissionais a se manterem na trajetória de melhoria na qualidade de ensino, sempre buscando elevar o nível de aprendizagem dos alunos ao longo dos anos" (SÃO PAULO, 2013). Cabe esclarecer que, desde o ano de 2001, os professores 
e diretores das escolas estaduais recebiam bonificações independentemente do resultado alcançado pelos alunos no SARESP. Além disso, é importante elucidar que a escola que não atinge as metas, ou que o faz parcialmente, não sofre nenhum tipo de sanção administrativa, tampouco há algum tipo de redução da carga horária dos professores ${ }^{14}$.

No ano de 2009, o adicional de qualidade (IQ), passou a ser considerado para pagamento do bônus. O IQ "reflete a posição do IDESP da escola em relação à média das escolas da rede e à meta de longo prazo" (SÃO PAULO, 2014, p. 12) e permite que a BR seja paga de acordo com o crescimento que a escola apresentou no período, mesmo que ela não atinja integralmente a meta estipulada. Algumas escolas não conseguem melhorar seu IDESP; às vezes, apresentam um retrocesso no índice se comparado ao do ano anterior. Se elas possuem, no entanto, um IQ razoável em relação às médias obtidas pelas diversas escolas estaduais naquele nível de ensino avaliado, é possível aos seus profissionais receberem a BR apenas pelo IQ. Contudo, os servidores das escolas que não apresentam nenhum avanço no período em pauta e cujo IQ é nulo, nada recebem.

\section{A Pesquisa Empírica e a Análise dos Dados}

A Diretoria de Ensino da Região de Pirassununga (DEP) possuía, no ano de 2011, 49 escolas de educação básica, compreendendo o ensino fundamental e o ensino médio. Foram selecionadas três escolas ${ }^{15}$ para a realização da pesquisa empírica com base nas médias alcançadas por elas no IDESP de 2009 e de 2010, na $8^{a}$ série do ensino fundamental ${ }^{16}$ : a escola Pintassilgo, localizada no centro do município de Pirassununga/SP e as escolas João de Barro e Canário, ambas da periferia do município de Araras/SP. Essas escolas têm prédios bem conservados e adequados ao processo educativo; apenas a escola João de Barro não contava com sala de leitura e de informática.

Os questionários ${ }^{17}$ aplicados junto aos alunos, pais e professores das três escolas foram formulados com questões fechadas (à exceção do questionário dos professores que continha uma questão aberta), totalizando, respectivamente: 242, 140 e 25 questionários coletados no segundo semestre de 2011. Também, nesse período, realizamos entrevistas com oito $^{18}$ dos nove dirigentes ${ }^{19}$ conselheiros de polos da SEE/SP: Fernandópolis, Ribeirão Preto, Sorocaba, Jundiaí, Registro, Pindamonhanguaba, José Bonifácio e Lins. No decorrer da pesquisa, percebemos a necessidade de entrevistar os diretore ${ }^{20}$ das escolas para conhecer a opinião deles sobre as possibilidades e desafios encontrados na implementação do PQE e o que eles conceituavam como uma educação de qualidade, entre outras questões. Essas entrevistas tiveram como base um roteiro anteriormente elaborado para as entrevistas com os dirigentes $^{21}$.

\section{- O tema da qualidade na educação para os diretores, alunos, professores e pais}

Para o diretor da escola Canário, a educação de qualidade é a que possui "foco na aprendizagem do aluno, oferece tudo que ele precisa para aprender, para mantê-lo na escola com aprendizagem".

$\mathrm{Na}$ opinião da diretora da escola João de Barro, a educação de qualidade é composta de três fatores:

$1^{\circ}$ ) a aula propriamente dita. Um professor que utiliza concepções de ensino-aprendizagem conforme currículo, de forma contextualizada; $2^{\circ}$ ) comprometimento dos pais; $3^{\circ}$ ) recursos materiais e espaço físico adequado (DIRETORA DA ESCOLA JOÃO DE BARRO). 
Percebemos que os diretores que integraram esta pesquisa relacionam a qualidade educacional com a aprendizagem dos alunos, com o trabalho pedagógico escolar, o preparo dos professores, os recursos materiais e os espaços adequados também são referenciados por uma das diretoras para compor essa qualidade.

No questionário dos alunos, enumeramos 21 fatores $^{22}$ que poderiam compor uma educação de qualidade, expostos aleatoriamente. Dentre esses fatores, os alunos deveriam assinalar apenas cinco que eles considerassem indispensáveis para uma boa educação.

O fator assinalado pelos alunos que apareceu em primeira colocação em duas escolas referiu-se a "professores competentes"; esse item, a existência de biblioteca e a de espaços adequados foram os mais indicados pelos alunos das três escolas.

O item "excursões" obteve uma alta incidência como fator de boa educação nas três escolas. Anísio Teixeira (1954), ao explicar a pedagogia de John Dewey, afirma que:

A educação é fenômeno direto da vida, tão inelutável como a própria vida. A contínua reorganização e reconstrução da experiência pela reflexão constitui o característico mais particular da vida humana [...]. Essa contínua reconstrução - em que consiste a educação - tem por fim imediato melhorar pela inteligência a qualidade da experiência. Analisando-a mentalmente, percebendo as relações que ela nos desvenda, ganhamos os conhecimentos necessários para dirigir, com mais segurança, nossas experiências futuras [...]. Enquanto vivo, eu não me estou, agora, preparando para viver e daqui a pouco, vivendo. Do mesmo modo eu não me estou em um momento preparando para educar-me e, em outro, obtendo o resultado dessa educação. Eu me educo através de minhas experiências vividas inteligentemente (TEIXEIRA, 1954, p. 10).

Acreditamos que as excursões podem favorecer uma aprendizagem prazerosa por meio da experiência lúdica dos alunos. A vinculação da escola com a sociedade, com a vida presente, pode tornar-se mais rica. Para os alunos, talvez essa seja uma maneira de se perceber esse vínculo.

Eles também identificaram como elementos menos importantes o tempo escolar e o tamanho das escolas.

Chama a atenção outros fatores comuns, listados como de maior importância para uma boa educação: reforço, bons funcionários e os Cadernos do Aluno ${ }^{23}$, em detrimento da existência de fanfarra, poucos alunos, amigos e atendimento médico. Em média, o item alimentação ficou com a nona colocação e o fator Cadernos do Aluno obteve a décima primeira posição, nas três escolas.

Isso indica que, para além do senso comum, que apregoa que os alunos são desinteressados, no seu conjunto, eles possuem uma opinião formada acerca do que compõe uma boa educação: professores competentes, bons funcionários, reforço, espaços adequados, biblioteca, excursões. Outros espaços de aprendizagem também são tidos como fatores importantes para uma qualidade educacional.

Solicitamos, em uma questão aberta, que os professores enumerassem cinco características de uma escola de qualidade, escrevendo-as em ordem decrescente de importância. De maneira geral, as respostas foram bem variadas de escola para escola, mas surgiram características com temáticas comuns, como por exemplo, a do trabalho docente. Essas características foram tabuladas de acordo com a frequência com que apareciam em determinada colocação, por escola. Os dados obtidos foram os seguintes:

Quadro 1 - Características de uma escola de qualidade para os professores 


\begin{tabular}{|c|c|c|c|}
\hline ORDEM & JOÃO DE BARRO & PINTASSILGO & CANÁRIO \\
\hline $1^{\mathrm{a}}$ & valorização docente & direção presente & ambiente propício \\
\hline $2^{\mathrm{a}}$ & interesse dos alunos & bons professores & espaço diferenciado \\
\hline $3^{\mathrm{a}}$ & Infraestrutura & normas combinadas & compromisso docente \\
\hline $4^{a}$ & família presente & participação das famílias & envolvimento da família \\
\hline $5^{a}$ & trabalho em equipe & gestão organizada/dedicada & aprendizagem por parte dos alunos \\
\hline
\end{tabular}

Destacam-se os fatores comuns às três escolas: família e professor. A família é chamada a participar para que os professores consigam uma educação de qualidade. Contudo, nas três escolas, a temática que envolve o professor suplanta em importância a participação das famílias. Eles apontaram a valorização, o compromisso e a competência do docente como os principais fatores para uma educação de qualidade, atribuindo um grau de importância semelhante a: infraestrutura, ambientes propícios e espaços diferenciados. Há consonância entre as respostas dos professores e dos diretores entrevistados ao enumerarem os docentes e as famílias dos alunos como fatores que compõem a qualidade educacional.

Ao analisar os fatores intervenientes da qualidade escolar brasileira, Silva (2009) lista aqueles internos e externos à escola que se refletem nessa qualidade. Vejamos os fatores externos:

a) Fatores socioeconômicos, como condições de moradia; situação de trabalho ou de desemprego dos responsáveis pelo estudante; renda familiar; [...] b) Fatores socioculturais, como escolaridade da família; tempo dedicado pela família à formação cultural dos filhos [...] c) Financiamento público adequado, com recursos previstos e executados; decisões coletivas referentes aos recursos da escola; conduta ética no uso dos recursos e transparência financeira e administrativa. d) Compromisso dos gestores centrais com a boa formação dos docentes e funcionários da educação [...] (SILVA, 2009, p. 4, grifos no original).

Ainda de acordo com Silva (2009), alguns fatores internos à escola sinalizam uma qualidade social da educação:

Organização do trabalho pedagógico e gestão da escola; os projetos escolares; as formas de interlocução da escola com as famílias; o ambiente saudável; a política de inclusão efetiva; o respeito às diferenças e o diálogo como premissa básica; o trabalho colaborativo e as práticas efetivas de funcionamento dos colegiados e/ou dos conselhos escolares (SILVA, 2009, p. 5).

Assim, fatores internos e externos inter-relacionados, e não apenas sobrepostos, constituiriam uma educação de melhor qualidade. Para os docentes, a escola detém um grande potencial para oferecer essa educação, visto que eles enumeraram muitos fatores internos que integram a educação de qualidade: a presença e a dedicação da direção, a competência e o compromisso do docente, as normas combinadas, o trabalho em equipe, o interesse dos alunos e a sua aprendizagem. Como fatores externos, eles apontaram: a valorização do docente, os espaços diferenciados e ambientes propícios, a infraestrutura, a presença, a participação e o envolvimento das famílias. Isso se mostrou interessante, já que 
a qualidade educacional não está, para a grande maioria dos docentes (76\%), explicitamente relacionada com a aprendizagem dos alunos.

A aprendizagem do aluno foi indicada apenas uma única vez e com um grau de importância menor que todos os outros fatores, na escola Canário; na escola Pintassilgo, os alunos não compuseram explicitamente um fator de qualidade para os professores e, na João de Barro, o interesse dos alunos apareceu como segundo fator de uma escola de qualidade, após a valorização docente. Tal ponto nos alerta para o problema com relação ao que se coloca hipoteticamente como qualidade da educação, do ponto de vista dos professores, e a realidade dos índices que tomariam a aprendizagem dos alunos como ponto fulcral. Parece haver uma dicotomia no tratamento dessa questão, especialmente nas escolas com índices mais baixos.

No questionário dos pais havia uma questão com 18 fatores que poderiam compor uma boa educação; eles deveriam escolher alguns deles.

Foi alta a incidência do fator tempo em duas das escolas pesquisadas (Canário e Pintassilgo), demonstrando que os pais valorizam a ampliação do tempo de permanência do aluno na escola. Na escola João de Barro, o fator preponderante foi a competência dos professores, para além do tempo de permanência. Isso pode indicar que a qualidade do trabalho é considerada mais importante que a extensão do tempo de jornada discente, na opinião desses pais. Os "Cadernos do Aluno" foram pouco assinalados perante os demais fatores enumerados.

Nas três escolas, o item "a escola avalia o trabalho dos professores" foi a opção escolhida pela maior parte dos pais se comparado ao fator "a escola avalia o aluno e o retém se ele não foi bem". Na escola Pintassilgo, a avaliação do trabalho do professor alcançou a primeira colocação dentre todas as opções apresentadas para compor uma educação de qualidade. Na escola Canário, esse item ficou em segundo lugar e, na escola João de Barro, em quarto. A avaliação dos professores não foi mencionada pelos docentes nem pelos diretores como fator de qualidade educacional, conforme vimos anteriormente.

Como nas escolas Pintassilgo e Canário houve um percentual significativo de pais que não atribuem qualidade à educação oferecida pela escola (por volta de $20 \%$ dos pais que responderam ao questionário) e que mudariam seu filho de escola se pudessem (cerca de $30 \%$ deles), inferimos que o PQE, como proposto pela SEE/SP, como uma avaliação institucional, goza de aceitação por parte da comunidade extraescolar. Ele pode responder à demanda da comunidade no que concerne à avaliação do trabalho desenvolvido pelas equipes escolares.

\section{- A organização das escolas em relação ao PQE}

Os alunos das três escolas apresentaram respostas muito parecidas quando perguntados se eles sentem-se pressionados pelos professores por causa das provas do SARESP. Somando-se as alternativas "sim" e "às vezes", percebemos que a grande maioria sente-se pressionada. O "não" representou 35\% das respostas. Essa pressão também é sentida pelos docentes: 55\% dos docentes da escola Canário, 62,5\% da escola João de Barro e 62,5\% dos docentes da escola Pintassilgo sentem-se pressionados para alcançar as metas estipuladas para a escola.

As respostas dadas pelos alunos, quando questionados sobre a realização de provas preparatórias para o SARESP, durante o ano, não causam estranheza, a média das escolas gira em torno de $80 \%$ nesse quesito, apontando a existência de uma organização por parte dos professores para preparar os alunos para o SARESP. Ao confrontarmos esses dados com os dados referentes à questão "Com que frequência, neste ano, você ouviu seus professores 
falarem do SARESP?", percebemos que poucos alunos (em média 5\% do total dos alunos entrevistados) afirmaram que seus professores não abordam o tema do SARESP ou que o fizeram uma ou duas vezes (por volta de $15 \%$ dos alunos entrevistados). Todos os demais alunos afirmam que o discurso docente sobre essa avaliação é ouvido com regularidade, quase todo mês ou semanalmente, nas escolas. Um dirigente de polo confirma isso:

Eu senti que o diretor passou a se envolver mais com o pedagógico, acompanhar mais, a se interessar mais. Essa meta, essa intenção comum de dar certo circula entre o diretor e o vice, os coordenadores, os supervisores, a oficina. E é claro que os professores todos são envolvidos nisso, porque quem tem de semear esse desafio e essa confiança na escola é a equipe gestora. Então, hoje, o diretor se envolve muito mais com o pedagógico. Há anos atrás eu sentia que havia muito mais a tendência do diretor [ficar] no administrativo, e hoje ele faz o equilíbrio. Esse é um ponto que destaco para falar para você (RIBEIRÃO PRETO).

Há provas preparatórias para o SARESP a fim de que os alunos tenham um desempenho melhor, ao passo que outros tempos e espaços de formação para desenvolver integralmente o aluno são desconsiderados.

Quanto ao IDESP, nas escolas Pintassilgo e João de Barro, 75\% dos docentes não o consideram um bom instrumento de avaliação da qualidade educacional e os outros $25 \%$ o veem como um bom recurso para tanto. Na escola Canário, 22\% assinalaram a alternativa "não sei responder" e 77\% responderam que o IDESP é um bom instrumento. A dissonância em relação ao IDESP pode ser explicada, na opinião de um dirigente, pela sua correlação ao pagamento de bônus:

Particularmente, preocupo-me com os critérios adotados para o pagamento do bônus. Às vezes, a conotação em relação ao prêmio deixa de ser vista como valorização e passa a ser vista como desestímulo por aqueles que nada recebem. [...] Acredito que os critérios para o recebimento do bônus devam ser alterados, principalmente levando-se em conta outros fatores, como por exemplo: vulnerabilidade social da comunidade onde a escola está inserida, módulo escolar deficitário, e não somente o desempenho e a evasão observados em cada unidade escolar. Enfim, o bônus mérito, como vem sendo oferecido, em vez de ser traduzido aos profissionais da educação como um estímulo, um desafio, passa a ser visto, em alguns casos, como um desestímulo para os profissionais da rede (PINDAMONHANGABA).

Foi perguntado aos professores: "O bônus funciona como uma motivação para você exercer o seu trabalho?". Nas três escolas, cerca de $75 \%$ dos docentes responderam que não e $25 \%$ que sim. É importante notar que dentre os que responderam aos questionários, apenas dois professores nunca haviam recebido a BR e assinalaram a resposta "não". Quanto ao bônus, um dirigente afirma que:

o feitiço virou contra o feiticeiro. Foi péssimo atrelar o bônus ao resultado porque eles quiseram responsabilizar a escola pelos resultados obtidos. É claro que nós temos responsabilidade. A escola tem uma porcentagem de responsabilidade, mas não é $100 \%$ [...]. Eu quero mostrar para eles, das várias fontes que estou estudando, os fatores que interferem na aprendizagem e fazer um paralelo com o que a Coordenadoria de Estudos e Normas Pedagógicas mandou para gente, no que tange aos fatores que 
interferem. E a conclusão é óbvia, não dá realmente para atrelar a obtenção de resultados a dinheiro, porque isso vira contra, só causa desestímulo [...] porque nós temos excelentes profissionais que não receberam e professores horríveis que receberam (JUNDIAÍ).

De posse dos dados coletados na pesquisa, verificamos que, apesar de afirmarem que a BR não os motiva, muitos professores acreditam que o IDESP é um bom instrumento para a avaliação da qualidade escolar. Isso pode ser uma explicação válida para a organização interna das escolas na qual os docentes cedem lugares e tempos pedagógicos para preparar os alunos para o SARESP. Outra explicação pode ser dada com o aporte do estudo de Bonamino e Sousa (2012) sobre as três gerações de avaliação da educação básica no Brasil. As autoras explicam que a primeira geração de avaliação consiste na avaliação diagnóstica, sem atribuição de consequências diretas, enquanto que "as outras duas gerações articulam os resultados das avaliações a políticas de responsabilização, com atribuição de conseqüências simbólicas ou matérias para os agentes escolares" (BONAMINO; SOUSA, 2012, p. 373) e afirmam que:

evidências nacionais e internacionais mostram que principalmente o uso de resultados das avaliações de terceira geração para informar iniciativas de responsabilização forte pode envolver riscos para o currículo escolar. Um deles é a situação conhecida como ensinar para o teste, que ocorre quando os professores concentram seus esforços principalmente nos tópicos que são avaliados e desconsideram aspectos importantes do currículo, inclusive de caráter não cognitivo (BONAMINO; SOUSA, 2012, p. 383, grifo no original).

\section{- O desempenho discente nos níveis de proficiência do SARESP em língua portuguesa e matemática (de 2008 a 2012) ${ }^{24}$}

As escolas pesquisadas apresentaram dificuldades em manter uma trajetória de melhoria do IDESP, comparando-se os resultados obtidos no período de 2008 a 2012.

Utilizando os resultados do primeiro e do último ano, percebemos que, em duas das três escolas pesquisadas (João de Barro e Canário), houve um aumento do percentual de alunos na proficiência Abaixo do Básico em língua portuguesa e matemática.

Ao somarmos os índices dessas duas disciplinas nas três escolas, em cada nível de proficiência, obtivemos, respectivamente, os seguintes percentuais para os anos de 2008 e 2012: Abaixo do Básico: 20\% e 23\%; Básico: 59\% e 55\%; Adequado: 20\% e 19\%; e Avançado: $1 \%$ e 3\%. Apesar de o percentual de alunos distribuídos pelos níveis de proficiência não apresentar grandes alterações entre os anos de 2008 e 2012, pudemos observar que houve um aumento no número de alunos nos níveis de proficiência extremos: Abaixo do Básico e Avançado, reflexo da diminuição nos níveis de proficiência Básico e Adequado.

Os dados revelam que um baixo percentual de alunos concentrados no nível Básico (4\%) e Adequado (1\%) estão migrando para os níveis Abaixo do Básico e Avançado. Isso aponta a dificuldade das equipes escolares em trabalhar com as diferenças individuais dos alunos no percurso escolar. Como vimos, no trabalho pedagógico, vários fatores internos e externos à escola interferem no processo ensino-aprendizagem, dentre os quais destacamos: os fatores socioeconômicos e socioculturais da comunidade intra e extraescolar, $o$ financiamento público, a formação docente e a organização do trabalho escolar. Não há 
como mensurar a qualidade da educação escolar sem controlar devidamente todas as variáveis externas.

Em março de 2014, a SEE/SP divulgou uma Nota Técnica do PQE, incorporando ao cálculo do Índice de Cumprimento de Metas (ICM) o Índice de Nível Socioeconômico (INSE), definido como a média do nível socioeconômico dos alunos de cada escola de acordo com as informações referentes à renda familiar, escolaridade do pai e da mãe, entre outras, retiradas dos questionários respondidos pelos pais, quando da aplicação do SARESP nos anos de 2008, 2009 e 2010.

Segundo a própria SEE/SP, a incorporação ao ICM do INSE representou um aprimoramento do modelo de Bonificação por Resultados (SÃO PAULO, 2014, p. 14) que, antes apresentava uma limitação séria:

O uso do indicador de resultado da escola para a comparação de escolas tem uma limitação séria. Tanto os alunos das escolas são diferentes, como as condições estruturais de cada escola são diferentes. Assim, as condições sociais dos alunos, principalmente o capital sociocultural de sua família, tornam o desempenho cognitivo mais ou menos difícil (SÃO PAULO, 2014, p. 14).

Brooke (2013) ao analisar políticas de responsabilização implantadas por alguns estados brasileiros sinaliza algumas dificuldades na utilização do nível socioeconômico e apresenta uma outra medida de desempenho discente, a avaliação longitudinal de desempenho dos alunos, desde que se tome como parâmetro uma primeira avaliação comum:

Não há duvida de que a melhor medida para o desempenho dos alunos seria a medida longitudinal em que os mesmos são monitorados ao longo de um período de tempo com base em uma primeira avaliação servindo de linha de base. $\mathrm{O}$ resultado destas medidas longitudinais, em termos de ganhos médios de aprendizagem da coorte de alunos, pode ser considerado um cálculo mais exato do valor agregado da escola porque além de controlar pelo efeito da aprendizagem prévia, controlam-se também as flutuações na composição das turmas (BROOKE, 2013, p. 58-59).

A nosso ver o modelo descrito por Brooke (2013), de monitoramento da aprendizagem dos alunos, tem a vantagem de possuir uma avaliação primeira como base para a análise do desempenho posterior, ou seja, do valor agregado da escola.

\section{Conclusão}

Percebemos que tanto na CF de 1988 como na LDBEN de 1996 determina-se a garantia de padrão de qualidade educacional, mas esse padrão não é explicitado. No primeiro documento, a educação como dever da família e do Estado é entendida de forma ampla, tendo como fins o pleno desenvolvimento da pessoa humana, o preparo para o exercício da cidadania e a sua qualificação para o trabalho. No segundo, estão postas as mesmas finalidades da CF de 1988, porém, o padrão de qualidade é definido como variedade e quantidades mínimas de insumos per capita.

Na década de 1990, para cumprir o preceito legal de garantia de um padrão de qualidade, o Ministério da Educação e do Desporto implantou o Sistema Nacional de Avaliação da Educação Básica, o SAEB, tendo o modelo CIPP como referência. Esse modelo, adaptado para o sistema educacional, considera o contexto, o insumo e o processo como fontes de informação; todavia, a ênfase está no produto, na proficiência discente 
aferida por meio de provas padronizadas para conferir qualidade à educação. O SAEB foi o marco inicial de um conjunto de ações articuladas de avaliação em larga escala que impulsionou a cultura avaliativa no país. Com a apresentação do Plano de Desenvolvimento da Educação, em 2007, foi instituído o Índice de Desenvolvimento da Educação Básica, o IDEB, como instrumento que combina informações sobre o desempenho dos alunos em exames padronizados e dados sobre a aprovação escolar, consubstanciando-os em índices.

Nesse contexto, o PQE foi inserido com o objetivo de avaliar a qualidade das escolas estaduais paulistas, monitorando seus resultados. O IDESP é o seu instrumento principal, o qual utiliza dados do desempenho discente aferidos em avaliações em larga escala e informações sobre o fluxo escolar, sintetizando esses dados em um índice. Ao modelo CIPP acrescentou-se outro componente: contexto + insumo + processo = resultado + bonificação. Como vimos, até o ano de 2014, o conceito de qualidade educacional estava restrito aos resultados mensuráveis, observáveis por meio de provas ou testes e informações sobre o fluxo escolar. Nas escolas públicas, o currículo oficial propõe o trabalho em torno de habilidades e competências que estão estreitamente relacionadas com as habilidades requeridas nas avaliações do SARESP (CASTRO, 2013).

Não há como discutirmos a qualidade educacional, entendida como uma educação ampla que forma os alunos nos aspectos históricos, culturais, econômicos, sociais e políticos, sem refletirmos sobre algumas questões imprescindíveis: as formas de financiamento público para viabilizá-la, estreitando a relação entre a riqueza produzida no Brasil (o PIB) e os gastos na educação básica; a necessidade de valorização do professor; a formação inicial e continuada de qualidade para o magistério; a viabilização de espaços e de tempos de aprendizagem adequados que propiciem a formação integral do aluno, desde a educação infantil.

O SARESP não pode substituir a própria finalidade das escolas, a formação integral do aluno para uma sociedade democrática. Espaços importantes, como por exemplo, os Grêmios Escolares e os diferentes colegiados que iniciam os alunos na experiência democrática, não são ocupados nas escolas para que os estudantes alcancem essa formação. Aulas de artes, educação física, história, filosofia, são menosprezadas em detrimento das de língua portuguesa e matemática. Quase tudo gira em torno do SARESP - o que importa é o alcance das metas. Segundo Brooke (2006), "se é evidente que a escola tem responsabilidade pela formação integral do aluno, ainda é necessário chegar a um consenso mais amplo sobre a legitimidade da responsabilização e sobre os indicadores da qualidade na educação" (BROOKE, 2006, p. 400).

A educação básica precária no início da escolaridade do professor, sua formação inicial como docente, que também é insuficiente, e a desvalorização de sua profissão são fatos que podem reverberar no aceite da pressão da SEE/SP para que os alunos alcancem as metas propostas pela SEE/SP, como forma de receber algum aumento pelo trabalho executado. A avaliação de meio torna-se o fim, a finalidade do processo educativo.

Para além de resultados aferidos em testes ou provas, acreditamos que uma educação de qualidade tem de ser pensada para a transformação da realidade, com melhor redistribuição da riqueza produzida no Brasil, em que exista respeito ao pleno exercício das liberdades civis, políticas e sociais dos indivíduos. O trabalho do professor, como um intelectual, torna-se essencial, assim como a escola pública, que é instrumento de coesão social, de preparo do futuro. Para isso, ambos, escola e professor, precisam estar preparados e ser valorizados por uma sociedade que efetivamente lide com o que projeta. 


\section{Referências}

AFONSO, A. J. Avaliação educacional: regulação e emancipação para uma sociologia das políticas avaliativas contemporâneas. 4. ed. São Paulo: Cortez, 2009.

ANDRADE, E. C. School Accountability no Brasil: experiências e dificuldades. Revista de Economia Política. São Paulo, v. 28, n. 3 (111), p. 443-453, jul./set. 2008.

BONAMINO, A.; SOUSA, S. Z. Três gerações de avaliação da educação básica no Brasil: interfaces com o currículo da/na escola. Educação e Pesquisa, São Paulo, v. 38. n. 2, p. 373 388, abr./jun. 2012. Disponível em: < http://www.scielo.br/pdf/ep/v38n2/aopep633.pdf>. Acesso em: 18 ago. 2015.

BRASIL. Constituição da República Federativa do Brasil, de 5 de outubro de 1988. Disponível em: <http://www.planalto.gov.br/ccivil_03/Constituicao/Constituicao.htm>. Acesso em: 31 maio 2013.

BRASIL. Lei $n^{\circ}$ 9.394, de 20 de dezembro de 1996. Estabelece as diretrizes e bases da educação nacional. Disponível em: <http://www.planalto.gov.br/ccivil_03/leis/19394.htm>. Acesso em: 31 maio 2013.

BRASIL. Ministério da Educação e Cultura. IDEB 2011, Brasil continua a avançar. [2011]. Disponível em: <http://portal.inep.gov.br/web/portal-ideb/portal-ideb〉. Acesso em: 18 set. 2012.

BRASIL. Parecer CNE/CEB nº 8, de 5 de maio de 2010. Estabelece normas para aplicação do inciso IX do artigo $4^{\circ}$ da Lei $n^{\circ}$ 9.396/96 (LDB), que trata dos padrões mínimos de qualidade de ensino para a Educação Básica pública. Disponível em: $<$ http://www.portal.mec.gov.br/índex.php?option=com_docman\&task $>$. Acesso em: 06 out. 2013.

BROOKE, N. O Futuro das políticas de responsabilização educacional no Brasil. Cadernos de Pesquisa, São Paulo, v. 36, n. 128, p. 377-401, maio/ago.2006. Disponível em: <http:// www.scielo.br/pdf/cp/v36n128/v36n128a06.pdf. >. Acesso em: 30 ago. 2015.

BROOKE, N. Sobre a equidade e outros impactos dos incentivos monetários para professores. Estudos em Avaliação Educacional, São Paulo, v. 24, n. 55, p. 34-62, abr./ago.2013. Disponível em:

<http://www.fcc.org.br/pesquisa/publicacoes/eae/arquivos/1813/1813.pdf>. Acesso em: 27 ago. 2015.

BUFFA, E. A questão das fontes de investigação em história da educação. In: Periódico do Mestrado em Educação da UCDB. Campo Grande, p. 79-86. jul./dez. 2001. (Série Estudos, n.12).

CASTRO, A. O Programa de Qualidade da Escola da Secretaria de Estado da Educação de São Paulo: o texto e o contexto em três escolas da Diretoria de Ensino - Região de Pirassununga. 2013. 217 p. Tese (Doutorado em Educação), Centro de Educação e Ciências Humanas, Universidade Federal de São Carlos, São Carlos: SP, 2013. 
CASTRO, M. H. G. Sistemas Nacionais de Avaliação e de Informações Educacionais. São Paulo em Perspectiva. v. 14, n. 1, jan/mar 2000. Disponível em: $<$ http://www.scielo.br/scielo .php?script=sci_arttext\&pid=s0120-88392000000100014 . Acesso em: 28 maio 2009.

KRUPPA, S.M.P. O Banco Mundial e as políticas públicas de educação nos anos 90. In: $24^{\mathrm{a}}$ Reunião anual da ANPED, 2001, Caxambú. Textos dos Trabalhos e Pôsteres da $24^{a}$ Reunião anual da ANPED, 2001. Disponível em: <http://24reuniao.anped.org.br/tp.htm\#gt5>. Acesso em: 08 set. 2015.

NOSELLA, P. A atual política para a educação do estado de São Paulo e da União: a cultura do desempenho. Revista APASE. São Paulo, ano IX, n. 11, p. 29-38, 2010.

OLIVEIRA, R. V.; NOVAES, L. C. Os efeitos dos resultados da avaliação externa e dos índices de desempenho escolar sobre a gestão da escola e do trabalho pedagógico na rede estadual paulista. In: Encontro Nacional de Didática e Práticas de Ensino - ENDIPE 16, 2012. Campinas. Anais do Encontro Nacional de Didática e Práticas de Ensino - ENDIPE 16. UNICAMP; Junqueira \& Marin Editores, 2012. Livro 1. p.503- 514.

PESTANA, M. I. G. S. Avaliação educacional: o sistema nacional de avaliação da educação básica. In: RICO, E. M. (Org.). Avaliação de políticas sociais: uma questão em debate. São Paulo: Cortez, 2009. p. 53-63.

SÃO PAULO (ESTADO). Secretaria de Estado da Educação. Resolução SE nº 27, de 29 de março de 1996. Dispõe sobre o Sistema de Avaliação de Rendimento Escolar do Estado de São Paulo. Disponível em: < http://siau.edunet.sp.gov.br/ItemLise/arquivos/27_1996.htm? Time=19/04/2016\%2015:38:25>Acesso em: 19 abr. 2016.

SÃO PAULO (ESTADO). Deliberação CEE no 09, de 4 de agosto de 1997. Institui, no sistema de ensino do Estado de São Paulo, o regime de progressão continuada no ensino fundamental. Disponível em < http://www.crmariocovas.sp.gov.br/pdf/ccs/Diretor2006/DiretorE_indicacao08_97_deliber ação09_97.pdf>. Acesso em: 18 abr. 2016.

SÃO PAUlO (ESTADO). Programa Estadual de Educação. São Paulo, 2007a. Disponível em: <http://www. saopaulo.sp.gov.br/acoes/educacao/metas/>. Acesso em: 26 ago. 2007.

SÃO PAUlO (ESTADO). Caderno do Programa de Qualidade da Escola. São Paulo: Imprensa Oficial do Estado de São Paulo, 2007b.

SÃO PAULO (ESTADO). Programa de Qualidade da Escola - Sumário Executivo. São Paulo: Imprensa Oficial do Estado de São Paulo, 2008a.

SÃO PAULO (ESTADO). Notícias. 2008b. Disponível em: <http:www.educacao.sp.gov.br/noticias_\%202008/2008_11_12.asp>. Acesso em: 12 dez. 2008.

SÃO PAULO (ESTADO). Resolução SE no 74, de 6 de novembro de 2008. [2008c]. Institui o Programa de Qualidade da Escola - PQE e o Índice de Desenvolvimento da Educação do Estado de São Paulo - IDESP. Disponível em: 
$<$ http://www.educacao.sp.gov.br/lise/sislegis/detresol.asp?strAto $=200811060074>$. Acesso em: 06 out. 2013.

SÃO PAULO (ESTADO). Lei Complementar $\mathrm{n}^{\circ} 1.078$, de 17 de dezembro de 2008. Institui Bonificação por Resultados - BR, no âmbito da Secretaria da Educação [2008d]. Disponível em: $<$ http://www .al. sp.gov.br/repositorio/legislacao/lei.complementar/2008/lei.complementar-107817.12.2008. html>. Acesso em: 19 abr. 2016.

SÃO PAULO (ESTADO). Matrizes de Referência para a Avaliação SARESP: documento básico. São Paulo: Imprensa Oficial do Estado de São Paulo, 2009.

SÃO PAULO (ESTADO). Programa de Qualidade da Escola - Nota Técnica. São Paulo: Imprensa Oficial do Estado de São Paulo, 2010. Disponível em: <http://www.educacao.sp.gov.br>. Acesso em: 23 abr. 2010.

SÃO PAUlO (ESTADO). Comunicado SE de 3 de abril de 2013. Assunto: Bonificação de Resultados - BR. São Paulo: Imprensa Oficial do Estado de São Paulo, 2013. 8 p.

SÃO PAUlO (ESTADO). Programa de Qualidade da Escola - Nota Técnica. São Paulo: Imprensa Oficial do Estado de São Paulo, 2014. Disponível no endereço eletrônico: <http://idesp.edunet.sp.gov. br/Arquivos/NotaTecnica2013.pdf.>. Acesso em: 09 fev. 2015.

SAVIANI, D. História das idéias pedagógicas no Brasil. 2. ed. rev. e ampl. Campinas, SP: Autores Associados, 2008. (Coleção memória da educação).

SILVA, M. A. Qualidade social da educação pública: algumas aproximações. Caderno CEDES, Campinas, v. 29, n. 78. maio/ago. 2009. Disponível em: <http://www.scielo.br/scielo .php?script=sci_arttext\&pid=s0101-32622009000200005>. Acesso em: 11 maio 2011.

SOUZA, A. M. A relevância dos indicadores educacionais para a educação básica: informação e decisões. In: SOUZA, A. M. (Org.). Dimensões da avaliação educacional. Petrópolis/RJ: Vozes, 2005a. p. 90-109.

SOUZA, A. N. A política educacional do Banco Mundial. In: BETTENCOURT, A. B.; OLIVEIRA JUNIOR, W. M. Estudo, pensamento e criação. Campinas, SP: Graf. FE, 2005b. Livro II, p. 99-117.

TEIXEIRA, A. Esboço da educação de John Dewey. In: DEWEY, J. Vida e educação. São Paulo: Melhoramentos, 1954. p. 7-29.

ZANARDINI, J. B. Ontologia e avaliação da educação básica no Brasil (1990-2007). 2008. 208 p. Tese (Doutorado em Educação). Centro de Ciências da Educação. Universidade Federal de Santa Catarina. Florianópolis: SC, 2008.

\footnotetext{
${ }^{1}$ Este trabalho dialoga com os dados da Tese de Doutorado, intitulada "O Programa de Qualidade da Escola da Secretaria de Estado da Educação de São Paulo: o texto e o contexto em três escolas da Diretoria de Ensino - Região de Pirassununga", defendida junto ao Programa de Pós-Graduação em Educação da Universidade Federal de São Carlos, em 2013 e que teve o apoio da Secretaria de Estado da Educação de São Paulo.
} 


\footnotetext{
${ }^{2}$ Secretaria de Estado da Educação de São Paulo (SEE/SP)

${ }^{3}$ Universidade Federal de São Carlos (UFSCar)
}

${ }^{4}$ O SARESP foi instituído pela Resolução SE no 27, de 29 de março de 1996, (SÃO PAULO, 1996) e consiste em um conjunto de provas elaborado sob a responsabilidade da SEE/SP, aplicado uma vez ao ano aos alunos das escolas estaduais paulistas, em determinados anos do ensino fundamental e médio. Língua portuguesa e matemática são as disciplinas que compõem o núcleo regular do SARESP; as demais são avaliadas de forma intermitente. As "Matrizes de Referência para a Avaliação SARESP: documento básico" (SÃO PAULO, 2009) explicitam as competências e habilidades mais gerais requeridas nas avaliações do SARESP para os alunos das $2^{\mathrm{as}}, 4^{\mathrm{as}}, 6^{\mathrm{as}}$ e $8^{\mathrm{as}}$ séries do ensino fundamental (respectivamente, no ensino fundamental de nove anos: $3^{\mathrm{os}}, 5^{\mathrm{os}}$, $7^{\text {os }}, 9^{\text {os }}$ anos) e $3^{\text {as }}$ séries do ensino médio.

${ }^{5}$ Cumprindo a Lei no 11.274 , de 6 de fevereiro de 2006, o estado de São Paulo iniciou a implantação do ensino fundamental de nove anos de maneira gradativa: a $1^{\mathrm{a}}$ série passou a denominar-se $2^{\mathrm{o}}$ ano e assim, sucessivamente.

${ }^{6}$ Em complementação à nota "d" deste texto, pode-se dizer que esse indicador combina informações de desempenho em exames padronizados (Prova Brasil ou SAEB) - obtido pelos estudantes ao final das etapas de ensino ( $4^{\mathrm{a}}$ e $8^{\mathrm{a}}$ séries do ensino fundamental e $3^{\mathrm{a}}$ série do ensino médio $)$ - com informações sobre rendimento escolar (BRASIL, 2011). O IDEB prevê metas de curto prazo, de dois em dois anos, e de médio prazo, até o ano de 2022, a serem alcançadas pelas unidades escolares, visando equiparar o desempenho das escolas brasileiras ao desempenho médio da educação básica dos países que compõem a Organização para a Cooperação e o Desenvolvimento Econômico (OCDE).

${ }^{7}$ Criado em 2007 pelo Instituto Nacional de Estudos e Pesquisas Educacionais Anísio Teixeira (INEP), "sintetiza dois conceitos igualmente importantes para a qualidade da educação: aprovação e média de desempenho dos estudantes em língua portuguesa e matemática. O indicador é calculado a partir dos dados sobre aprovação escolar, obtidos no Censo Escolar, e médias de desempenho nas avaliações do Inep, o Saeb e a Prova Brasil. A série histórica de resultados do Ideb se inicia em 2005, a partir de onde foram estabelecidas metas bienais de qualidade a serem atingidas não apenas pelo País, mas também por escolas, municípios e unidades da Federação" (BRASIL, 2011, s/p.).

${ }^{8}$ Diante do conjunto de fórmulas apresentado para o cálculo do IDESP, julgamos adequado nos ater àquela que oferece elementos para a discussão proposta neste artigo. A Nota Técnica do PQE explicita todas as fórmulas utilizadas no IDESP (SÃO PAULO, 2010), entre elas o cálculo do Índice de Cumprimento de Metas (ICM) de cada escola. Os critérios de apuração e de avaliação estão descritos na Resolução Conjunta da CC/SF/SEP/SGP - 1, de 10 de março de 2009.

${ }^{9}$ No ano de 1998, com a publicação da Deliberação CEE n ${ }^{\circ}$ 09, de 4 de agosto de 1997, o ensino fundamental (EF), na rede pública estadual de São Paulo, foi dividido em ciclos: ciclo I ( $1^{\mathrm{a}}$ a $4^{\mathrm{a}}$ séries) e ciclo II $\left(5^{\mathrm{a}}\right.$ a $8^{\mathrm{a}}$ séries). Com a Resolução SE $n^{\circ} 74 / 2013$ o EF foi reorganizado em três ciclos: I - Ciclo de Alfabetização, do $1^{\circ}$ ao $3^{\circ}$ anos; II - Ciclo Intermediário, do $4^{\circ}$ ao $6^{\circ}$ anos; III - Ciclo Final, do $7^{\circ}$ ao $9^{\circ}$ ano. O aluno não pode ser retido, por baixo rendimento, nos anos que compõem esses ciclos à exceção do último ano de cada um.

${ }^{10}$ Ensino médio (EM).

${ }^{11}$ Essas metas são divulgadas no Boletim da Escola, onde constam as médias alcançadas pela escola em cada nível, no ano anterior, e as metas estipuladas para o ano subsequente. Há índices, nesse boletim, referentes à Diretoria de Ensino (DE), à rede estadual, entre outros, além da distribuição percentual dos alunos nos diferentes níveis de proficiência de cada disciplina avaliada e nos níveis de desempenho alcançados na redação.

${ }^{12}$ A Lei Complementar $n^{\circ} 1.078$, de 17 de dezembro de 2008, instituiu a Bonificação por Resultados - BR, no âmbito da SEE/SP. Essa lei prevê, no seu artigo $1^{\circ}$, o pagamento de bônus a cada servidor "em efetivo exercício na Secretaria da Educação, decorrente do cumprimento de metas previamente estabelecidas, visando à melhoria e ao aprimoramento da qualidade do ensino público". A BR é desvinculada dos vencimentos ou salários e somente será paga se as metas estipuladas para a unidade escolar em que o servidor atua forem alcançadas, naquele período. O cálculo para o pagamento, feito no ano subsequente, é "sobre até $20 \%$ (vinte por cento) do 
somatório da retribuição mensal do servidor relativo ao período de avaliação" (art. $9^{\circ}$ da LC no 1.078, de 17 de dezembro de 2008).

${ }^{13}$ Desde o ano de 2007, há, nas escolas públicas estaduais da SEE/SP (com seis ou mais classes), professores designados pelo diretor para atuar na função de Professores Coordenadores no ensino fundamental ou no ensino médio, com uma jornada de 40h/semanais (Resolução SE nº 88, de 19 de dezembro de 2007, alterada pela Resolução SE nº 42, de 10 de abril de 2012).

${ }^{14}$ Em 2008 e 2009, o pagamento da BR foi feito apenas para os profissionais que trabalhavam em escolas que cumpriram integralmente a meta (SÃO PAULO, 2008d). A partir de 2010, ocorreram mudanças: mesmo que a meta não fosse plenamente atingida, o pagamento seria realizado e calculado de acordo com a melhora apresentada pela escola em relação ao índice do ano anterior, por meio do Índice de Cumprimento de Metas (IC).

${ }^{15}$ Utilizaremos os nomes fictícios Pintassilgo, João de Barro e Canário para nos referirmos às escolas pesquisadas.

${ }^{16}$ Elas foram escolhidas porque apresentaram as seguintes características: a escola Pintassilgo obteve o índice mais baixo da DEP no ano de 2009 e, no ano de 2010, encontrava-se entre as unidades com os índices mais baixos; a escola João de Barro apresentou o melhor índice da DEP nos anos de 2009 e de 2010; e a escola Canário manteve um índice médio mais constante (o seu índice variou $-1 \%$ de 2009 a 2010), nos anos pesquisados, em relação às outras escolas. Tomando-as como os três casos possíveis frente aos parâmetros postos pelo IDESP, acreditamos que critérios utilizados para essa escolha vão na direção de pesquisas em educação que tem "procurado estudar o particular, considerando suas vinculações com o universal" (Buffa, 2001, p. 83).

${ }^{17} \mathrm{O}$ instrumento de coleta de dados junto aos alunos possuía 11 questões que se voltavam para: tempo de estudo naquela escola; opinião acerca da qualidade da educação da escola e sobre quais fatores compõem uma boa educação; avaliação com relação à utilização e ao alcance dos Cadernos dos Alunos (currículo oficial da SEE/SP); função do SARESP, como se lida com ele na escola e se eles se sentem pressionados por esse mecanismo geral de avaliação do ensino; e finalmente, o que é o IDESP. Nove questões compunham o instrumento que se voltou para os pais, versando sobre: o nível de escolaridade do respondente; o tempo (anos) que o filho (a) matriculado na $8^{\text {a }}$ série frequentava a escola pública; se tinha ou teve outros filhos estudando na escola; as características de uma educação de qualidade, na opinião dele (a); se a escola oferecia uma educação de boa qualidade; se mudaria o filho (a) de escola se pudesse; há quantas reuniões compareceu na escola durante o ano; se o filho (a) se sentia pressionado por causa das avaliações do SARESP; e se o ensino melhorou com a adoção dos Cadernos dos Alunos. Os dados buscados pelo questionário junto ao professor continha dez tópicos acerca: do tempo de experiência docente e na escola; de informações sobre o recebimento do bônus; da sua opinião com relação a se o bônus funcionava como uma motivação para exercer o trabalho; da pressão para o alcance das metas; do seu conhecimento de como era calculado o IDESP; do seu posicionamento sobre o IDESP ser ou não um bom instrumento para avaliar a qualidade das escolas; das características que comporiam uma escola de boa qualidade; do principal objetivo do PQE e, por fim, de suas considerações sobre o currículo oficial.

${ }^{18}$ Apesar do nosso esforço, um deles não nos concedeu a entrevista.

${ }^{19} \mathrm{O}$ dirigente regional de ensino tem suas atribuições conferidas pelo artigo 90 do Decreto $\mathrm{n}^{\circ} 57.141$, de 18 de julho de 2011. A nomeação do funcionário da carreira do magistério para atuar como dirigente é feita pelo Secretário de Estado da Educação. O dirigente conselheiro possuía a função de orientar e repassar as informações emanadas dos órgãos centrais aos dirigentes regionais das Diretorias de Ensino (DEs) que compunham o respectivo polo sob sua responsabilidade.

${ }^{20}$ Quatro pessoas exerceram a função de diretor na escola Pintassilgo, no período da coleta de dados, o que inviabilizou o alcance dos objetivos pretendidos com a entrevista.

${ }^{21} \mathrm{O}$ roteiro de entrevistas era composto de 21 itens agregados em três subtítulos: o processo de elaboração do $\mathrm{PQE}$ e a participação dos atores educacionais; a implantação do PQE e, por fim, a sua implementação. 
${ }^{22}$ É importante ressaltar que os fatores que integraram essa questão foram retirados de nosso trabalho cotidiano na supervisão de ensino na SEE/SP na região, das conversas informais com diferentes colegas no trabalho educacional; não houve nenhuma pesquisa prévia para escolher os itens que poderiam ou não ser colocados nessa questão.

${ }^{23}$ Currículo oficial da SEE/SP elaborado no formato de apostilas consumíveis entregues aos alunos desde o ano de 2009.

${ }^{24}$ É imprescindível esclarecer que, consoante os objetivos da pesquisa aqui apresentada, não tivemos a pretensão de avaliar as escolas, mas discutir a implementação do Programa de Qualidade da Escola. Por isso, não procuramos instituições que apresentaram uma diferença significativa nesses dois anos de avaliação; tentamos conhecer como essas escolas se organizaram, ou não, em relação ao PQE.

Recebido: Abril/2016.

Aprovado: Março/2017. 